\title{
Who can prevent diabetes? Current issues in the prevention of type 2 diabetes
}

\author{
${ }^{1} \mathrm{E}$ Goyder, ${ }^{2} \mathrm{R}$ Simmons, ${ }^{3} \mathrm{M}$ Gillett \\ ${ }^{1}$ Section Director and Reader in Public Health Medicine, School of Health and Related Research (ScHARR), University of Sheffield; \\ ${ }^{2}$ Career Development Fellow, MRC Epidemiology Unit, Cambridge; ${ }^{3}$ Research Fellow, ScHARR, University of Sheffield, Sheffield, UK
}

\begin{abstract}
Research evidence supports the widely held view that much of the current and growing disease burden associated with diabetes in the UK is due to sedentary lifestyles and dietary trends and is therefore preventable in principle. However, prevention is dependent on the implementation of affordable and effective interventions that will encourage behaviour change, increasing physical activity levels and modifying low-fibre, calorie-dense diets. Both population-wide and individual-based intervention/prevention strategies may be feasible and costeffective, but there are a number of key outstanding uncertainties that require both further research and economic modelling to resolve. The potential for harms to outweigh benefits when implementing preventive interventions, and for health inequalities to be exacerbated when promoting behaviour change, means that guidance must consider ethics as well as effectiveness. The nature and scale of the challenge faced means that societal as well as individual and community change will be required.There are synergies between diabetes prevention strategies and wider public health priorities in relation to both chronic disease prevention and global climate change, but strong advocacy and leadership from the health sector will be required if we are to seize the opportunity to reverse current trends.
\end{abstract}

\author{
Correspondence to E Goyder, \\ Public Health Section, School of \\ Health and Related Research, \\ University of Sheffield, Regent \\ Court, 30 Regent Street, \\ Sheffield SI 4DA, UK \\ e.goyder@sheffield.ac.uk \\ doi: I0.4997/JRCPE.20I0.SOI
}

DECLARATION OF INTERESTS No conflict of interests declared.

\section{INTRODUCTION}

Diabetes prevention efforts to reduce the morbidity and mortality associated with the condition are an international public health concern. The need for urgent action has been highlighted by the International Diabetes Federation (IDF). ${ }^{1,2}$ The increasing priority given to prevention in the UK was demonstrated in 2008 when the first Diabetes UK Frontiers in Diabetes conference focused on barriers to prevention. The recent Diabetes UK policy report focuses on prevention and prediabetes. ${ }^{3}$

There are a number of existing reviews in this field, most recently an evidence update completed by Simmons et al. for the IDF. ${ }^{4}$ There are a number of areas where the potential for public health benefits might be significant, but where, in the absence of clear evidence for the effectiveness and cost-effectiveness of policies, current guidance is largely based on expert consensus.

The aim of this paper is to highlight some of the major issues raised by the question 'Who can prevent diabetes?', drawing on international evidence and framing the issues in a UK context, using recent national policy documents. It takes a broad public health definition of prevention, including both primary prevention and secondary prevention (screening and early detection). It aims to provide a starting point for debate about current priorities, the need for further research to support policy and practice and the role that could be played by healthcare professionals in achieving diabetes prevention at individual, community and population levels.

\section{CURRENT NATIONAL POLICY DIRECTIONS}

There is already evidence-based guidance on the prevention of obesity and overweight and the promotion of healthy lifestyle choices produced by both SIGN and NICE and a number of relevant Cochrane Collaboration reviews (see Table I). In the past year both English and Scottish Departments of Health have published relevant policy and consultation documents. These address screening and intervention programmes for diabetes and cardiovascular risk but focus on different populations. The Scottish Better Diabetes Care consultation document clearly identifies a number of relevant ongoing programmes ('Keep Well' and 'Well North') which have targeted deprived communities and remote rural communities respectively. The English Department of Health is targeting families with its 'Change4Life' programme, developing 'LifeCheck', an online health service to help middle-aged individuals assess and manage their own health, and has recently introduced 'NHS Health Check', which offers five-yearly vascular risk assessments to all 40-74-yearolds in the population. ${ }^{5}$

Raising awareness of risk more widely in the general population has been pursued through national media 
TABLE I Evidence-based guidance and systematic reviews

\section{SIGN guidelines}

Adult obesity: http://www.sign.ac.uk/pdf/sign8.pdf

Child obesity: http://www.sign.ac.uk/pdf/sign69.pdf

CVD prevention: http://www.sign.ac.uk/pdf/sign97.pdf

NICE clinical guidelines

Obesity: http://guidance.nice.org.uk/CG43

\section{NICE public health guidance}

Physical activity guidance: $\mathrm{PH} 2, \mathrm{PH} 8, \mathrm{PHI}$, $\mathrm{PHI} 7$

Primary care: http://guidance.nice.org.uk/PH2

Physical activity/environment: http://guidance.nice.org.uk/PH28

Workplace: http://guidance.nice.org.uk/PHI3

Young people: http://guidance.nice.org.uk/PHI7

Behaviour change: http://guidance.nice.org.uk/PH6

\section{Diabetes prevention in high-risk populations}

(guidance in preparation)

http://guidance.nice.org.uk/PHG/Wavel 9/6

http://guidance.nice.org.uk/PHG/Wavel 9/62

\section{Cochrane Collaboration Systematic Reviews}

(www.cochrane.org/reviews)

- Dietary advice for prevention of type 2 diabetes

- $\quad$ Zinc supplementation for the prevention of type 2 diabetes mellitus

- Wholegrain foods for the prevention of type 2 diabetes mellitus

- Alpha-glucosidase inhibitors for people with impaired glucose tolerance or impaired fasting blood glucose

- Exercise or exercise and diet for preventing type 2 diabetes mellitus

- Exercise for overweight or obesity

- Long-term non-pharmacological weight loss interventions for adults with prediabetes

- Long-term pharmacotherapy for obesity and overweight

- Psychological interventions for overweight or obesity

- Low glycaemic index or low glycaemic load diets for overweight and obesity

Health Technology Assessment (HTA) Programme:

- Waugh N, Scotland G, McNamee P et al. Screening for type 2 diabetes: literature review and economic modelling. Health Technol Assess 2007; I I: I-1 44.

- Gillett M, Royle P, Snaith A et al. Non-pharmacological interventions to reduce the risk of diabetes in people with impaired glucose regulation: systematic review and economic evaluation. (publication due June 2010)

campaigns, most directly through the Diabetes UK campaigns 'Measure Up' and 'Silent Assassin'. To date, the focus of policy initiatives and national campaigns has been on awareness raising, the identification of individuals at risk and on encouraging individual lifestyle change rather than wider societal, environmental or regulatory change. In order to better understand the impact of policy on relevant individual behaviours, there is a need to develop pragmatic policy options across a wide spectrum of potential fields, including both individual behavioural interventions and environmental interventions (such as the development of safe walking and cycling routes) and regulatory interventions (such as clearer food labelling) so that their impact can be evaluated in 'real-world' settings. Evidence that can inform policy, in relation to both population and individual level interventions, is discussed below.

\section{CURRENT EVIDENCE FOR THE EFFECTIVENESS OF POPULATION-LEVEL INTERVENTIONS}

There is little direct evidence for the impact of populationlevel interventions on reducing diabetes risk in UK populations. However, the modest changes in behaviour seen in prevention trials suggest that interventions to promote similar goals in the general population might be feasible. ${ }^{6}$ The trends in body mass index (BMI) and sedentary lifestyles associated with an increasingly 'obesogenic' environment indicate that reversing current trends requires small but significant shifts in activity and dietary patterns - the 'small change' approach. ${ }^{7,8}$ Therefore, more attention needs to be given to understanding the determinants of behaviours linked to chronic disease at the population level and on the evaluation of efforts to shift the entire distribution of behaviour.

Health-promotion programmes are increasingly using tools and techniques from social marketing - defined by the National Social Marketing Centre as 'the systematic application of marketing techniques and approaches to achieve specific behavioural goals, to improve health and reduce health inequalities'. Recent systematic reviews and policy reports have summarised the types of evidence available to date on physical activity and dietary change, which is promising but not conclusive. ${ }^{9,10}$ There is also a growing interest in the development of interventions based on individual target-setting linked to financial incentives for achieving targets, linked in turn to physical activity or weight loss. ${ }^{11-13}$

As some ethnic minority, socio-economically deprived and specific 'hard-to-reach' communities (such as gypsy travellers) are known to be at increased risk of diabetes, there is a need to develop culturally appropriate interventions that facilitate behaviour change. Dietary habits and patterns of physical activity are recognised to be largely influenced by environmental, financial and cultural factors. ${ }^{14}$ The feasibility and acceptability of both individual- and population-level diabetes prevention strategies should therefore be evaluated in specific communities and across a range of settings. ${ }^{15}$ Both nonrandomised pragmatic evaluations and qualitative studies of barriers to and facilitators of change are required to increase our understanding of 'what works, how, and for whom'.

\section{CURRENT EVIDENCE FOR THE EFFECTIVENESS OF INDIVIDUAL-LEVEL INTERVENTIONS}

Diabetes prevention research has largely focused on identifying individuals at high risk through screening and treating those with non-diabetic hyperglycaemia with intensive lifestyle or drug interventions. ${ }^{2}$ There is clear evidence for the potential to prevent diabetes from 
international trials in people with impaired glucose tolerance (IGT), and long-term results from these studies are promising. ${ }^{16-18}$ The current challenge is that of translating trial findings into 'real-world' prevention programmes. ${ }^{4}$ There has been some progress in the design and evaluation of more pragmatic diabetes prevention initiatives. ${ }^{19-23}$ However, there remain many complex challenges for the real-world adaptation of diabetes prevention study ${ }^{24}$ (DPS)-like or diabetes prevention programme ${ }^{25}$ (DPP)-like interventions in the community. There is also a need to consider how we best balance ensuring the effectiveness of interventions with a minimisation of costs and improved sustainability when scaling up trial interventions. ${ }^{26}$ In particular, there is concern about the effectiveness of interventions in high-risk populations outside the context of clinical trials since behaviour change and medication adherence is difficult to sustain without supportive physical, social and cultural environments.

Some of the uncertainties relating to screening for undiagnosed prevalent diabetes and the effectiveness of earlier intervention have been resolved since these were identified by the IDF consensus statement. The AngloDanish-Dutch study of intensive treatment of people with newly diagnosed diabetes in primary care (ADDITION) involves a screening phase to identify previously undiagnosed diabetes followed by a pragmatic open-label cluster randomised controlled trial comparing the effect on cardiovascular risk of intensive multifactorial therapy with standard care. ${ }^{27}$ Initial data from ADDITION suggest that people with diabetes detected by screening do have an adverse but modifiable cardiovascular risk profile at diagnosis. ${ }^{28,29}$ One-year follow-up in the Cambridge and Dutch ADDITION arms found that cardiovascular disease risk factors had improved since diagnosis and were significantly lower among patients in the intensive treatment arm..$^{30,31}$

A controlled trial examining the psychological impact of stepwise screening for diabetes (ADDITION-Cambridge) by comparing participants invited for screening with those not invited suggested that anxiety, depression, worry about diabetes and self-rated health were not significantly different between those invited for screening and controls. This is reassuring and suggests that stepwise screening with appropriately informed consent is associated with limited psychological harm. ${ }^{32,33}$

Although these results suggest that screening for diabetes and intensive modification of cardiovascular risk are both feasible, the main determinant of the effectiveness and cost-effectiveness of diabetes screening is the magnitude of cardiovascular risk reduction following early detection and intensive treatment, which remains uncertain.

In terms of the practicalities of screening programmes, it is still unclear how best to target screening invitations, how often to rescreen and how to tackle problems of uptake, particularly among individuals at high risk. The evaluation of the national pilot screening programme for type 2 diabetes in deprived areas of England identified a number of problems with implementing diabetes screening in high-risk communities. ${ }^{34}$ Screening for diabetes inevitably finds many more people at increased risk than people with the disease, including many with impaired glucose regulation who we know would also benefit from behaviour change interventions. It remains unclear how to effectively intervene to reduce risk for these individuals when there are limited resources for individualised support. The English 'Health Checks' programme ${ }^{5}$ will inevitably identify large numbers of people who might benefit from interventions to reduce their risk of cardiovascular disease and diabetes, and should provide opportunities to evaluate different risk identification and intervention strategies in a 'real-world' context.

\section{ECONOMICS OF DIABETES PREVENTION: COST-EFFECTIVENESS AND AFFORDABILITY}

Key uncertainties around the impact of population-level interventions and how to effectively deliver interventions in community settings are linked to uncertainties about the economics of diabetes prevention. There is concern about the benefits of relatively low-intensity interventions in less selected populations compared to the effectiveness in prevention trial participants, and the resources needed to sustain behavioural changes or medication adherence. Moreover, cost-effectiveness does not imply affordability and the significant up-front costs of prevention programmes impose a need to find more efficient ways of achieving benefits.

Which interventions are most likely to be cost-effective?

For individuals with impaired glucose tolerance, lifestyle intervention, ${ }^{24,25,35-37}$ rosiglitazone, ${ }^{38}$ metformin $^{25,35}$ and acarbose $^{39}$ have all been shown to prevent progression to diabetes. However, health economic studies suggest the most cost-effective interventions are likely to be intensive lifestyle interventions (and/or metformin) in high-risk groups. ${ }^{2}$ Evidence suggests that lifestyle intervention is likely to be more effective than drug management in the long term. However, outside the context of a clinical trial, maintaining behaviour change may be difficult. The potential impact of side effects of drugs and issues of adherence in a community setting need to be a considered, as does the desirability of medicalising those with prediabetes. However, for some patients, switching to metformin may be a pragmatic approach and modelling suggests this could be a cost-effective strategy. ${ }^{40}$

Addressing uncertainty about longer-term benefits and effectiveness of 'real-world' community interventions

In the future we will have more data from long-term follow-up of participants in randomised controlled trials with robust outcome data. This will enable us to predict 
E Goyder, R Simmons, M Gillett

with more certainty the long-term clinical and economic impacts of both diabetes prevention and screening programmes. The relative cost-effectiveness of upstream interventions at the population level will be harder to establish with any certainty. As personal behaviours take time to change and the health benefits can take even longer to establish, ${ }^{41}$ the delayed effects of small lifestyle changes will be difficult to measure and it may not be possible to confidently attribute population-level secular trends to specific prevention measures. However, benefits can be modelled based on cohort study evidence that behaviour reliably predicts health outcomes, and assuming the observed relationships are causal.

Most economic studies lack long-term follow-up data (greater than 10 years) from DPS and rely on computer simulation modelling to predict the long-term clinical impact of DPPs and associated economic impact. Data from ongoing community-based studies are likely to be of shorter duration so models need to adopt conservative assumptions regarding sustained reductions in risk of diabetes and demonstrate the effect of using a much shorter time horizon model. Sufficient follow-up is required to show the effect of any 'maintenance' intervention. In the absence of such evidence, cost-effectiveness evaluations of community interventions will need to rely on reductions in risk of diabetes estimated through changes in glycaemia measures or other intermediate measures such as weight change and exercise.

\section{Evidence gaps}

There are some key issues that contribute to the uncertainty around the cost-effectiveness of the prevention of diabetes, some of which will be addressed by current trials, including ADDITION ${ }^{27}$ In particular, we lack evidence to model the natural history of diabetes from onset to clinical diabetes and the sustained effectiveness of both population-level and individual interventions.

It is important that the number of uncertain parameters in economic models does not lead to undue scepticism about their value. Probabilistic sensitivity analysis allows uncertainty around effectiveness and other model parameters to be taken account of, resulting in estimates of how likely interventions are to be cost-effective. Combined with sensitivity analyses that test the effect on results of altering key assumptions and time horizons, such analyses can help to inform decisions that inevitably involve uncertainty in the short term. Longer-term results from trials are still needed to confirm benefits predicted by models of intervention effects.

The cost-effectiveness of prevention is likely to change over time, since more effective management of glycaemia or related complications will reduce the marginal costeffectiveness of earlier intervention. Equally, the costeffectiveness of screening will be reduced if primary prevention policies are effective.

\section{ETHICAL ISSUES}

Since prevention - both primary (i.e. interventions in populations and individuals who do not have diabetes or who have non-diabetic hyperglycaemia) and secondary (i.e. screening to identify those with undiagnosed diabetes) - involves interventions that will have an impact on healthy individuals, not all of whom will directly benefit, there are specific ethical implications to consider. As well as weighing potential harms and benefits of prevention, there are trade-offs between respecting individual autonomy and the wider public health benefits of active intervention.

The Nuffield Bioethics Council's Impacts on autonomy and personal freedom: $a$ useful framework for considering public health interventions is based on the extent to which interventions impact on personal freedom. ${ }^{42}$ The intervention levels considered range from 'do nothing', 'provide information' and 'enable choice' through 'guide choice' and 'restrict choice' to 'eliminate choice'. Because there are a large variety of potential diabetes prevention interventions in the 'provide information' category (e.g. calorie counts on all restaurant menus, clearer food labelling) and 'enable choice' category (e.g. better facilities to encourage walking and cycling; free or cheap provision of fruit and vegetables) there may be an ethical argument that these are preferable to interventions which restrict choice (banning specific foods from shops or from school lunch-boxes). However, it is also possible that focusing on the provision of information, better facilities and more choice frequently benefits the better off - whose purchasing decisions may be more influenced by nutritional information than price, for example. So policy decisions must also take account of potential impacts on inequality and how these can be mitigated.

\section{Informed consent for screening}

Gaining fully informed consent for diabetes or prediabetes screening is a complex process, and the way in which screening is explained may have a direct impact on uptake and outcomes. ${ }^{43}$ Data from a controlled trial of stepwise screening for diabetes are reassuring and suggest that there are limited psychological harms associated with the screening process. ${ }^{32,33}$ Although there is growing evidence that screening does not result in significant 'false reassurance', ${ }^{44}$ ideally if an individual has modifiable risk factors (particularly if they are overweight and have a sedentary lifestyle) they need effective support for making lifestyle changes, whatever their screening test result.

\section{Unintended impacts on health inequalities}

Behaviour change interventions, including screening and information provision/awareness raising, may be more effective in better-off populations and may actually exacerbate health inequalities. Guidance therefore needs to consider how to mitigate any potential adverse impact on inequalities. 


\section{IDENTIFYING SYNERGIES BETWEEN DIABETES PREVENTION AND OTHER POLICY PRIORITIES}

\section{Preventing diabetes or promoting healthy lifestyles?}

A narrow focus on diabetes is likely to underestimate the true impact on population health of individual and collective interventions to promote change in key health behaviours such as diet and physical activity. Most effective diabetes prevention interventions are likely to help reduce cardiovascular disease and cancer risk, as well as improving mental health and social and emotional well-being.

The advantage of highlighting the wider and more immediate benefits of healthier lifestyles is that the message may be seen as more widely applicable and a positive message be viewed more effectively that a negative one (immediate health benefits rather than avoiding or delaying a hypothetical condition that might occur in the future). The advantage of a focus on diabetes prevention may be to focus and personalise the message for individuals and communities known to be at significantly increased risk of diabetes, such as specific ethnic minority communities.

\section{Preventing diabetes, tackling climate change and achieving social inclusion goals}

The recent Foresight report on obesity ${ }^{45}$ took a broad view of the factors influencing current obesity trends and identified some important potential synergies in term of policies and actions that would reduce obesity while achieving other (non-health) major policy goals specifically tackling climate change and tackling social exclusion - and the same is true of diabetes prevention policies. Many of the examples the report gives of relevant policy initiatives are directly applicable to diabetes prevention: designing sustainable communities and implementing sustainable food policies and active transport policies to increase walking and cycling. Similarly, there is a strong case for addressing socioeconomic inequalities as an underlying driver of unhealthy behaviours. ${ }^{46}$

\section{CONCLUSIONS}

In considering 'Who can prevent diabetes?' the conclusions of the recent Foresight report on obesity are relevant:

The evidence is very clear that policies aimed solely at individuals will be inadequate and that simply increasing the number or type of small scale interventions will not be sufficient to reverse this trend... a bold whole system approach is critical from production and promotion of healthy diets to redesigning the built environment to promote walking, together with wider cultural changes to shift

\section{KEY POINTS}

- There is already some relevant, evidence-based guidance in this field published by NICE, SIGN and Diabetes UK which, although not all specifically developed for those at increased risk of diabetes, addresses both population-level interventions to increase physical activity and change dietary habits and individual-level interventions for those already overweight or obese.

- Identifying individuals with impaired glucose tolerance and using intensive behaviour change interventions can reduce risk of diabetes in the context of randomised trials. Drugs - and surgery - to manage hyperglycaemia and obesity can also reduce risk of progression to diabetes in those unresponsive to behavioural interventions.

- There is less direct evidence that population-wide or community-level interventions or screening and individual-level intervention outside the context of trials are effective and cost-effective in reducing diabetes risk. In the context of these uncertainties, modelling potential costs and benefits may help identify an appropriate balance between individual and population-level interventions.

- Prevention programmes should take account of ethical considerations, including the impact on inequalities. Interventions should ideally be designed to mitigate the exacerbation of inequalities by investing in measures that target populations and individuals at risk of poorer health outcomes, ensuring interventions are both accessible and appropriate.

- There are potentially strong synergies between diabetes prevention strategies and other major and urgent public health priorities including climate change, socio-economic inequality, obesity prevention and reducing the burden of chronic diseases.

societal values around food and activity. This will require a broad set of integrated policies including both population and targeted measures and must necessarily include action not only by government, both central and local, but also action by industry, communities, families and society as a whole. ${ }^{45}$

Collectively, we will need to enlist all available evidence to develop and advocate evidence-based interventions that if implemented on a large enough scale will have a measurable impact on the population risk of diabetes and associated harms. There are synergies between diabetes prevention strategies and wider public health priorities in relation to both chronic disease prevention and global climate change, but strong advocacy and leadership from the health sector will be required if we are to seize the opportunity to reverse current trends. 
E Goyder, R Simmons, M Gillett

\section{REFERENCES}

I World Health Organization. Screening for type 2 diabetes. Geneva: WHO; 2003.

2 Alberti KG, Zimmet P, Shaw J. International Diabetes Federation: a consensus on type 2 diabetes prevention. Diabet Med 2007; 24:45I-63. doi:I0.IIII/j. I464-549I.2007.02I57.x

3 Diabetes UK. Prediabetes. Preventing the type 2 diabetes epidemic London: Diabetes UK; 2009.

4 Simmons RK, Unwin N, Griffin SJ. International Diabetes Federation: an update of the evidence concerning the prevention of type 2 diabetes. Diabetes Res Clin Pract 2009; 87:143-9. doi:10.1016/j.diabres.2009.10.003

5 Department of Health. Putting prevention first. Vascular checks: risk assessment and management. London: $\mathrm{DOH} ; 2008$.

6 Simmons RK, Harding AH, Jakes RW et al. How much might achievement of diabetes prevention behaviour goals reduce the incidence of diabetes if implemented at the population level? Diabetologia 2006; 49:905-II. doi:I0.1007/s00125-006-0I63-1

7 Unal B, Critchley JA, Capewell S. Small changes in United Kingdom cardiovascular risk factors could halve coronary heart disease mortality. J Clin Epidemiol 2005; 58:733-40. doi:10.1016/j.jclinepi.2004.09.015

8 Hill JO. Can a small-changes approach help address the obesity epidemic? A report of the Joint Task Force of the American Society for Nutrition, Institute of Food Technologists, and International Food Information Council. Am J Clin Nutr 2009; 89:477-84. doi:10.3945/ajcn.2008.26566

9 Stead M, Gordon R, Angus K et al. A systematic review of social marketing effectiveness. Health Educ 2007; 107:|26-9|. doi:10.1108/09654280710731548

10 Jebb S, Steer T, Holmes C. The 'Healthy Living' Social Marketing Initiative: a review of the evidence. London: Department of Health; 2007.

I I Marteau TM,Ashcroft RE, Oliver A. Using financial incentives to achieve healthy behaviour. BMJ 2009; 338:bl4I5. doi:I0.1 I36/bmj.bI4I5

12 Le Grand J, Srivastava D. Incentives for prevention. London: Health England; 2009.

13 Sutherland K, Leatherman S, Christianson J. Paying the patient: does it work? London: Health Foundation; 2008.

14 Egger G, Swinburn B. An "ecological" approach to the obesity pandemic. BMJ 1997; 315:477-80.

15 Netto G, Bhopal R, Khatoon J et al. Health promotion and prevention interventions in Pakistani, Chinese and Indian communities related to CVD and cancer: a review of the published evidence in the UK, other parts of Europe and the United States. Edinburgh: NHS Scotland; 2008.

16 Li G, Zhang P, Wang J et al. The long-term effect of lifestyle interventions to prevent diabetes in the China Da Qing Diabetes Prevention Study: a 20-year follow-up study. Lancet 2008; 37I:1783-9. doi:10.1016/S0140-6736(08)60766-7

17 Lindstrom J, llanne-Parikka P, Peltonen $M$ et al. Sustained reduction in the incidence of type 2 diabetes by lifestyle intervention: followup of the Finnish Diabetes Prevention Study. Lancet 2006; 368:1673-9. doi:I0.1016/S0I40-6736(06)6970I-8

18 Diabetes Prevention Program Research Group. I0-year follow-up of diabetes incidence and weight loss in the Diabetes Prevention Program Outcomes Study. Lancet 2009; 374:1677-86. doi:10.1016/ SOI40-6736(09)6I457-4

19 Absetz P, Oldenburg B, Hankonen $\mathrm{N}$ et al. Type 2 diabetes prevention in the real world: three-year results of the GOAL lifestyle implementation trial. Diabetes Care 2009; 32:1418-20. doi: $10.2337 / \mathrm{dc} 09-0039$

20 Kilkkinen A, Heistaro S, Laatikainen T et al. Prevention of type 2 diabetes in a primary health care setting. Interim results from the Greater Green Triangle (GGT) Diabetes Prevention Project. Diabetes Res Clin Pract 2007; 76:460-2. doi:10.1016/j.diabres.2006.09.027

21 NSW Health. Prevent Diabetes, Live Life Well Project. Available from: http://www.livelifewell.nsw.gov.au/livelifewell/diabetes/index.html

22 Ackermann RT, Finch EA, Brizendine E et al.Translating the Diabetes Prevention Program into the community. The DEPLOY Pilot Study. Am J Prev Med 2008; 35:357-63. doi:10.1016/j.amepre.2008.06.035
23 Lipscomb ER, Finch EA, Brizendine E et al. Reduced 10-year risk of coronary heart disease in patients who participated in a community-based diabetes prevention program: The DEPLOY pilot study. Diabetes Care 2009; 32:394-6. doi:I0.2337/dc08-1622

24 Tuomilehto J, Lindstrom J, Eriksson JG et al. Prevention of type 2 diabetes mellitus by changes in lifestyle among subjects with impaired glucose tolerance. N Engl J Med 200I; 344:1343-50. doi:10.1056/NEJM20010503344I80I

25 Knowler WC, Barrett-Connor E, Fowler SE et al. Reduction in the incidence of type 2 diabetes with lifestyle intervention or metformin. N Engl J Med 2002; 346:393-403. doi:I0.1056/NEJMoa0125I2

26 Ackermann RT, Marrero DG, Hicks KA et al. An evaluation of cost sharing to finance a diet and physical activity intervention to prevent diabetes. Diabetes Care 2006; 29:1237-4I. doi:10.2337/ dc05-1709

27 Lauritzen T, Griffin S, Borch-Johnsen K et al. The ADDITION study: proposed trial of the cost-effectiveness of an intensive multifactorial intervention on morbidity and mortality among people with type 2 diabetes detected by screening. Int J Obes Relat Metab Disord 2000; 24(Suppl 3):S6-II.

28 Echouffo-Tcheugui JB, Sargeant LA, Prevost AT et al. How much might cardiovascular risk be reduced by intensive therapy in people with screen-detected diabetes? Diabet Med 2008; 25:1433-9. doi:I0.I I I I/j. I 464-549I.2008.02600.x

29 Sandbaek A, Griffin S), Rutten G et al. Stepwise screening for diabetes identifies people with high but modifiable coronary heart disease: the ADDITION study. Diabetologia 2008; 5I:I127-34. doi: 10.1007/s00I25-008-1013-0

30 Griffin S, Wareham NJ, Kinmonth AL et al. Does intensive treatment of screen-detected diabetes improve outcomes? One year impact on cardiovascular risk factors in the ADDITION (Cambridge) trial. Amsterdam: European Association for the Study of Diabetes; 2007.

31 Janssen PG, Gorter KJ, Stolk RP et al. Randomised controlled trial of intensive multifactorial treatment for cardiovascular risk in patients with screen-detected type 2 diabetes: I-year data from the ADDITION Netherlands study. Br J Gen Pract 2009; 59:43-8. doi: I0.3399/bjgp09X39485 I

32 Eborall H, Davies R, Kinmonth $A$ et al. Patients' experiences of screening for type 2 diabetes: prospective qualitative study embedded in the ADDITION (Cambridge) randomised controlled trial. BMJ 2007; 335:490. doi:10.1 I36/bmj.39308.392176.BE

33 Eborall HC, Griffin SJ, Prevost AT et al. Psychological impact of screening for type 2 diabetes: controlled trial and comparative study embedded in the ADDITION (Cambridge) randomised controlled trial. BMJ 2007; 335:486. doi:10.1136/ bmj.39303.723449.55

34 Goyder E,Wild S, Fischbacher $\mathrm{C}$ et al. Evaluating the impact of a national pilot screening programme for type 2 diabetes in deprived areas of England. Fam Pract 2008; 25:370-5. doi:10.1093/fampra/cmn054

35 Ramachandran A, Snehalatha C, Mary S et al. The Indian Diabetes Prevention Programme shows that lifestyle modification and metformin prevent type 2 diabetes in Asian Indian subjects with impaired glucose tolerance (IDPP-I). Diabetologia 2006; 49:289-97. doi: 10.1007/s00 I25-005-0097-z

36 Pan XR, Li GW, Hu YH et al. Effects of diet and exercise in preventing NIDDM in people with impaired glucose tolerance. The Da Qing IGT and Diabetes Study. Diabetes Care 1997; 20:53744. doi:10.2337/diacare.20.4.537

37 Kosaka K, Noda M, Kuzuya T. Prevention of type 2 diabetes by lifestyle intervention: a Japanese trial in IGT males. Diabetes Res Clin Pract 2005; 67:152-62. doi:10.1016/j.diabres.2004.06.010

38 Dagenais GR, Gerstein HC, Holman R et al. Effects of ramipril and rosiglitazone on cardiovascular and renal outcomes in people with impaired glucose tolerance or impaired fasting glucose: results of the Diabetes REduction Assessment with ramipril and rosiglitazone Medication (DREAM) trial. Diabetes Care 2008; 31:1007-|4. doi:10.2337/dc07-1868 
Who can prevent diabetes?

39 Chiasson JL, Josse RG, Gomis R et al. Acarbose for prevention of type 2 diabetes mellitus: the STOP-NIDDM randomised trial. Lancet 2002; 359:2072-7. doi:I0.10I6/S0I40-6736(02)08905-5

40 Gillett M, Waugh N, Brennan A et al. Cost effectiveness of a 2-step lifestyle or metformin strategy for prevention of type 2 diabetes. Barcelona: 2nd World Congress on Controversies to Consensus in Diabetes, Obesity and Hypertension; 2008.

$4 \mathrm{I}$ Woolf $\mathrm{SH}$. A closer look at the economic argument for disease prevention. JAMA 2009; 30I:536-8. doi:I0.100I/jama.2009.5I

42 Nuffield Bioethics Council. Public health: ethical issues. Cambridge: Nuffield Foundation; 2007
43 Edwards A, Unigwe S, Elwyn G et al. Effects of communicating individual risks in screening programmes: Cochrane systematic review. BMJ 2003; 327:703-9. doi: I0.I I36/bmj.327.74I 7.703

44 Paddison CA, Eborall HC, Sutton S et al. Are people with negative diabetes screening tests falsely reassured? A parallel group cohort study embedded in the ADDITION (Cambridge) randomised controlled trial. BMJ 2009; 339:b4535. doi: I 0.I I36/bmj.b4535

45 Foresight. Tackling obesities: future choices. London: Government Office for Science; 2007.

46 Wilkinson R, Pickett K. The spirit level - why more equal societies almost always do better. London: Penguin; 2009. 